This item was submitted to Loughborough's Research Repository by the author.

Items in Figshare are protected by copyright, with all rights reserved, unless otherwise indicated.

\title{
An enquiry-based assessment strategy for the study of global information ethics
}

PLEASE CITE THE PUBLISHED VERSION

PUBLISHER

(c) Higher Education Academy Subject Centre for Information and Computer Sciences (ICS)

LICENCE

CC BY-NC-ND 4.0

REPOSITORY RECORD

Cooke, Louise. 2019. "An Enquiry-based Assessment Strategy for the Study of Global Information Ethics". figshare. https://hdl.handle.net/2134/3280. 
This item was submitted to Loughborough's Institutional Repository by the author and is made available under the following Creative Commons Licence conditions.

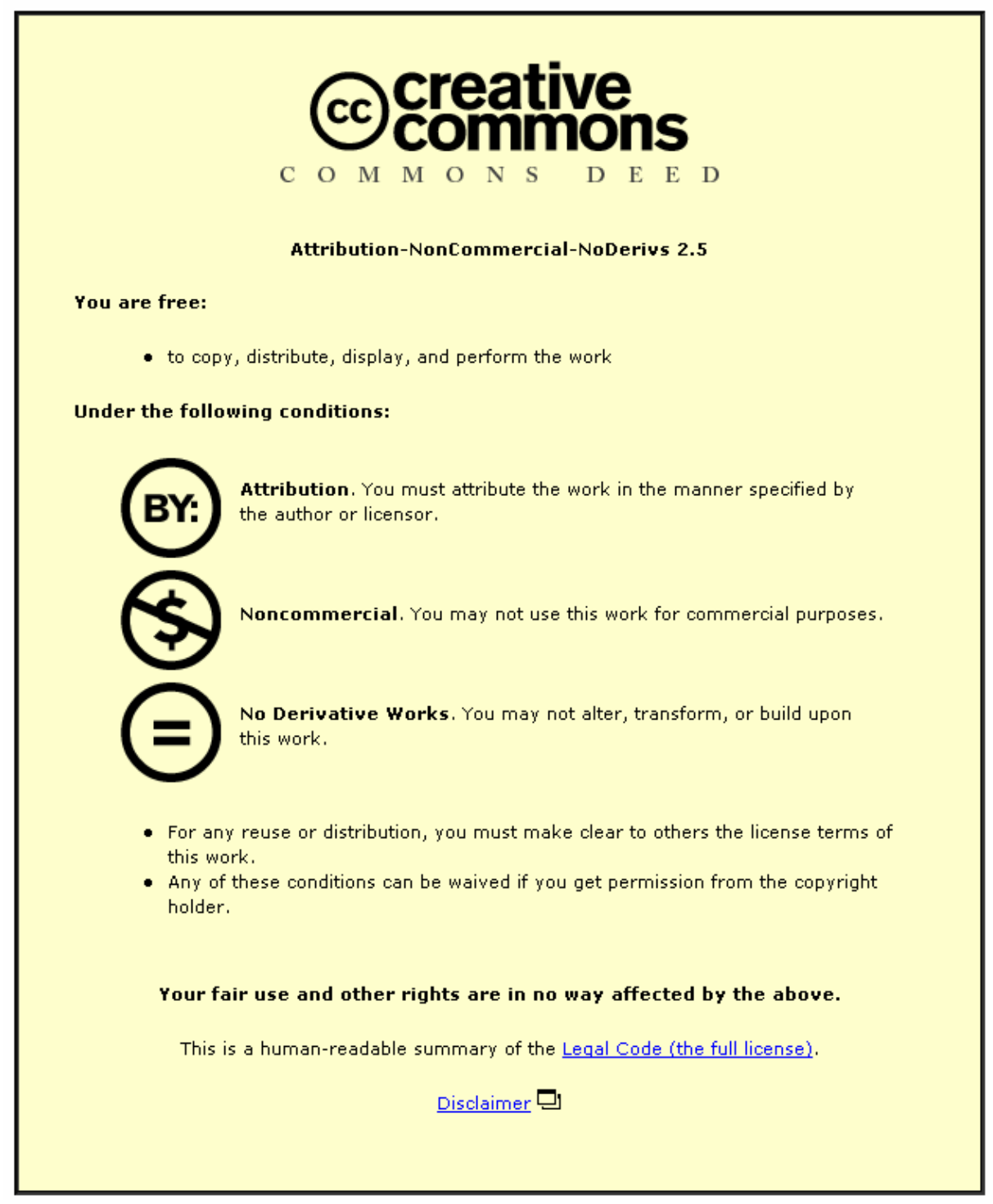

For the full text of this licence, please go to: http://creativecommons.org/licenses/by-nc-nd/2.5/ 


\title{
AN ENQUIRY-BASED ASSESSMENT STRATEGY FOR THE STUDY OF GLOBAL INFORMATION ETHICS
}

\author{
Louise Cooke \\ Loughborough University \\ Loughborough \\ Leicestershire LE11 3TU I.cooke@lboro.ac.uk \\ http://www.lboro.ac.uk/departments/dis/people/lcooke.html
}

\begin{abstract}
A case study is presented describing a particular approach to assessment that was adopted for a postgraduate elective module entitled "Libraries and Publishing in the Information Society". The assignment included a group research and presentation task analysing barriers to information flows in a country of the groups' own choice. Students had access to group discussion boards to help them complete the task. This was complemented by an individual written account in which students reflected on their own learning and on their performance in accomplishing the task. The rationale behind the mode of assessment was the integration of transferable skills into the curriculum; the development of a value-led approach to learning about ethical issues in a global information society; and the encouragement in students of a reflective approach to their own practice.
\end{abstract}

\section{Keywords}

Case study, assessment, information society, discussion boards, reflective practice, group work.

\section{ACKNOWLEDGEMENTS}

The author would like to acknowledge her thanks to the MSc students at City University taking the Libraries and Publishing in the Information Society module in the Academic Year 2004 - 2005 on whose enthusiasm and industriousness this paper is based. All student quotations are cited anonymously, and students' prior permission was obtained for the use of their comments.

\section{INTRODUCTION}

This paper presents a case study of an enquiry-based approach to facilitating student learning with regard to the ethical dimensions of a global information society. Enquiry-Based Learning (EBL) is based on the solution of a 'problem' or issue. Students work in small groups, and use the 'EBL process' to identify their learning needs in addressing this problem or issue. They will subsequently be responsible for carrying out the necessary research and investigation to provide an answer. Although more commonly called 'Problem-Based Learning' (PBL), the term EBL is preferred here as it emphasises the enquiry process undertaken by students rather than focussing on the problem itself. Proponents of EBL advocate its suitability as a method that helps students to develop problem-solving skills, reasoning and analytical skills, deep learning and self-directed learning (Brock, 2003; Savin-Baden, 2000).

The case study presented here concerns a postgraduate elective module for full- and part-time students taking MSc programmes in Information Science, and in Library and Information Studies at City University, London. It focuses on the assessment strategy adopted for the module. Although the individual elements of the assessment process (group presentation and individual reflective account) are not in themselves especially unusual, used in combination with an EBL approach and supported by online group discussion forums they proved to be very effective for teaching - or more appropriately, helping students to learn - about issues that are context-sensitive and value-critical.

The module, entitled "Libraries and Publishing in the Information Society", was intended to help students to develop a critical understanding of the broader social, economic, public policy and organisational contexts that affect the provision, supply, management and consumption of information services. A complementary aim was to provide a theoretical grounding in the analysis of the information society and the role of libraries, publishers, 
the media and information professionals within an information society. In addition to information society theory, subject content included national information policies, e-democracy and access to community information, the digital divide and the impact of globalisation on the media and information industries. Twenty-four students took the module in Spring 2005 during the final Semester of their taught programme. Contact sessions included tutor presentations, group and plenary discussions, guest lectures and a visit to a media information service. Face-to-face teaching was supported by learning materials and discussion boards available on the University's Virtual Learning Environment (VLE) using the WebCT software platform. The case study discusses the assessment element of the module, as it is argued that this acted as a powerful mechanism for enhancing student learning.

\section{Group Presentations}

\subsection{The Research Task}

During their first taught session, students were introduced to this element of the assessment process. The task required them to work in small groups (four students per group) carrying out research and then presenting their combined findings to the whole group during the scheduled session in week five. The majority of the research and presentation preparation was carried out outside of taught sessions. The groups were selfselected, using the group sign-up sheets available on the VLE.

The research task involved the groups selecting a specific country other than the UK - this could be a European or a non-European nation. With regard to their chosen country, they were to conduct a brief analysis of the current position of the information sector, identifying factors that were impacting on information flows and access to information within the country. It was suggested that they consider at least three of the following factors:

- Government policies and initiatives relating to the information sector;

- Relevant legislation (including, where appropriate, the impact of legislation from transnational bodies such as the EU);

- Demography and geography;

- Cultural, historical and social context;

- Political and economic context;

- Technological development;

- Literacy and educational levels;

- Access to library facilities.

Assessment criteria included evidence of critical analysis of the information obtained, and the extent to which they had identified and communicated the link between factors that had been analysed and their impact on information access and flow.

\subsection{Rationale}

A primary aim of this part of the assessment strategy was to embed the transferable skills of independent critical research, team working, presentation, time management and personal organisation into the curriculum. This need has long been - and continues to be - much emphasised within the discipline area by employers and professional bodies (for example, see CILIP, 2004; Gorman, 2004; McAllister and Alexander, 2003; Martin, 1989) and is embedded within the Quality Assurance Agency (QAA) disciplinary benchmark statement (Quality Assurance Agency, 2000) ${ }^{1}$. A secondary aim was to help students to develop a value-critical approach to difficult information policy issues such as censorship and the digital divide.

\subsection{The Role of Technology}

In order to help the groups communicate and work collaboratively, each group had their own individual discussion forum on the VLE. This allowed them to share their thoughts and discuss their progress, arrange face-to-face meetings, and share files and resources, safe in the knowledge that students outside their group could not "listen in". The module tutor, however, did have access to these groups, and at times intervened to offer support, comment or advice. Indeed, these boards proved to be an exceptionally useful means of

\footnotetext{
1 The QAA benchmark statements are a framework of specifications developed by panels of academics in the UK to define the intended learning outcomes of academic programmes within each discipline area.
} 
monitoring student progress, and helped the tutor to identify when groups were struggling or had unresolved 'group issues'. Even more usefully, perhaps, it gave the tutor a genuine insight into the process adopted by the groups to achieve the objectives of the assignment, rather than simply seeing the end product (Kolb, $1984)^{2}$.

\subsection{Student Responses}

Although some students expressed initial reservations at the prospect of having to work collaboratively and of having to give a presentation to their peers, they all threw themselves more or less enthusiastically into the research challenge. It was clear to the tutor from the activity within the discussion forums that the students were engaging with the task, and making steady progress. The groups chose an interesting (and adventurous) range of countries on which to focus their research. Thus, Argentina, Australia, China, Cuba, Greece, India and Ireland were all subject to analysis. This resulted in some fascinating presentations, identifying a wide range of different barriers to information flows such as poverty and economic downturn; a lack of network infrastructure and of public internet access points; monopolisation and conglomeration of news and media industries; government censorship; the geographic isolation of rural communities; skills shortages and a lack of training opportunities; illiteracy; and linguistic diversity. A particularly useful outcome of the presentations was a clear identification that significant barriers to full information access were a feature of developed western economies as well as of those of developing nations, whether as a result of factors such as an internal 'social digital divide' (Norris, 2001) or as a result of issues such as the centralisation of ownership and control of media outlets.

At the same time, the groups identified a number of positive measures that have been taken by national governments to increase information flows, particularly with regard to increasing internet access. An example that was provided of this was the measures adopted by the Argentinean government to promote the production of Spanish language internet content. Students demonstrated a mature approach to the evaluation of information sources relating to their respective countries and the potential for bias to creep in: this was particularly true of the group who were studying Cuba, who noted in their presentation that they were critically aware of the fact that "Much of the material on Cuba has a strong ideological slant that shapes its own version of the "truth"." Another interesting outcome of the work, which again became evident from monitoring of the group discussion board conversations, was the attention that students afforded to the pedagogical aspects of their presentation. An illustration of this point is the suggestion to her peers of one student on the discussion board that "...We need to get the audience thinking about the subject - perhaps we could put questions up then supply the answer etc...or leading statements."

\section{THE REFLECTIVE ACCOUNT}

\subsection{The Assignment Brief}

The group presentations accounted for only $10 \%$ of the total marks awarded for the module. It was made clear to students that, in the absence of any strong evidence that contributions to the team effort were not comparable, the marks would be allocated equally to all members of the group. It was up to them to make sure that everyone pulled their weight! The remaining module marks were awarded for an individual 2,000 2500 word account. This was intended to build on the work already carried out in the group task, and required students to provide a written account of their findings regarding information flows - and barriers to information access - within their chosen country, evidencing their own individual evaluation of the material. In addition to an account of their main findings, the assignment asked them to reflect on the lessons that they had learnt in the course of carrying out the group task. This could include reflection on what they had learnt about generic (rather than country-specific) issues impacting on information flows and access to information; on the process of preparing a group presentation; on what they had learnt from observing the presentations given by other groups; and on any other learning from the exercise that they felt might be of potential relevance and application to their own future practice.

\subsection{Rationale}

This task was intended to consolidate and extend student learning with regard to the work that they had already carried out on global information contexts and information flows. It also served to 'compensate' for the equal distribution of group marks for the first assignment task: it seemed reasonable to hypothesise that students who had engaged more fully with the presentation research and preparation, would find this part of

\footnotetext{
${ }^{2}$ This point has been further developed elsewhere: see Jones and Cooke (2006) for in-depth discussion.
} 
the assignment easier to complete and would probably produce better work. In addition, an important element was to develop students' capacity to reflect on their own learning, and to apply that learning to their own professional context.

\subsection{Student responses}

Although the final work submitted for this part of the assessment was of an almost universally high standard, the majority of students appeared initially to struggle with the concept of reflection, and found the notion of writing in a reflective style very difficult. Although they were given some early advice as to what reflective writing involved, they were so used to having to write in an impersonal style following standard academic conventions, that they struggled to get to grips with a less formal, reflective approach. The tutor therefore prepared some additional learning materials on reflection as a process and on reflective writing as a style ${ }^{3}$ : these were made available to students via the VLE. Surprisingly, some of the students who initially appeared to find the concept of reflection most difficult were also those who produced the best work in response to this part of the assessment.

\section{Evaluation AND REFLECTION}

This section relates specifically to evaluation of, and reflection on, the assessment strategy for the module, although it is recognised that this was such an integral part of the module learning that it is difficult (and possibly not desirable) fully to disentangle feedback from the one aspect. In order to achieve an objective evaluation of the strategy, the module tutor was able to draw on a range of data sources in addition to her own reflections, thus providing a triangulation of evidence. This also enabled evaluation to be situated at both Levels One and Two of Kirkpatrick's evaluation model (Kirkpatrick, 1977, cited in Forsyth et al, 1999), namely reaction (measurement of the learner's feelings and opinions), and learning (measurement of the facts, skills and attitudes the learner has gained from the event), as outlined below.

\subsection{Reaction}

Students' responses to the assessment could be measured using a range of sources: these included the formal module feedback; their 'reflective feedback' in the second part of the assignment; comments made in the online group forums; and informal comments made directly to the tutor.

With regard to formal module feedback, students are invited to rate on a scale of $1-6$ their level of agreement with a number of different statements, where $6=$ high agreement, and $1=$ low agreement. The statement that "The module assessment supported my learning" received an average rating of 4.9. The statements that "I have appreciated the opportunities for engagement and discovery" and that "I have enjoyed the module" received average ratings of 5.5 and 5.7 respectively. Although these latter two statements did not relate specifically to the assessment strategy, given its centrality to the mode of delivery of the module itself, it would seem reasonable to infer a connection between their responses to these statements and their views of the assessment tasks. Students are also asked to answer an open-ended question about the positive and negative aspects of the module. On the positive side, students commented that they had enjoyed doing the group presentations. However, one student commented negatively about the reflective part of the assignment. Interestingly, one student also noted that the module would be better suited for study as a core module in the first semester as "many of the concepts explored were important as a basis for librarianship and information studies". This seemed to be a mature recognition of the centrality of ethical and social issues to the discipline area.

The written reflective accounts produced by students offered another source of module feedback. These have to be interpreted with considerable caution - as the accounts were being assessed by the module tutor, students may well have felt it prudent to put forward favourable reflections on the module! Nevertheless, the accounts appeared to be very open and mature, and gave the module tutor some unexpected insights into how the students had reacted to the group research and presentation work. On the negative side, a number of students had highlighted the difficulties inherent in carrying out group work, especially with regard to the problem of "free-loaders" who did not pull their weight. They did, however, recognise that this was a problem that they were likely to encounter in the workplace, and that learning to manage such situations is an important work and life skill. They had also encountered some organisational issues, particularly where groups contained a mix of full- and part-time students or where illness or family circumstances had prevented attendance at the University. In this respect, they had appreciated the flexibility offered by the online discussion boards, enabling much of the co-ordinating work to be conducted virtually. A particularly interesting issue raised by several students was the difficulty they experienced in ceding 'control' to the group: one noted the difficulty in reaching

${ }^{3}$ The work of Drew and Bingham (2001) was very helpful in preparing these materials. 
a consensus over the presentation with others who held "different world views", and another student noted how they had had to become open to "different working styles". One group had encountered differences of opinion over the pedagogical style to be adopted for the presentation.

However, despite these difficulties, most students commented that overall they had found this exercise to be both interesting and enjoyable, and that they had learnt a lot from the process. This is summarised effectively in the comments of one student, who had had a particular aversion to the notion of group work. She wrote:

"I found certain elements of this type of teamwork quite taxing. Given the choice, I would rather come to conclusions on my own and according to my own logic. I work in a very ordered and precise manner and am meticulous when it comes to detail. Being put in a situation where I did not have absolute control, and where I was expected to compromise these ideals, was a steep learning curve for me."

However, her reflections continued:

"Overall, I would say that I have found this whole process utterly absorbing, not just for the research undertaken, but for the introspective examination it has provoked. I have discovered that despite my natural inclination towards detail and exactness, I am able to relinquish some control. Looking back, I can appreciate the team effort put into our presentation and am very proud of the outcome."

As noted earlier, monitoring and moderation of the group discussion boards also afforded the tutor a qualitative insight into students' engagement with the group task. The high volume of activity on the group boards indicated that students were making good progress with their research. It was interesting to note how they used the forum to encourage and motivate each other, making frequent comments such as "great stuff", "it's looking good", "keep going", and so on. In addition, the tutor was able to "audit" the quality of the intellectual debate in which students engaged: for example, one group debated extensively on the role of ethnicity as a barrier to information access, with one student maintaining that this was not relevant as it was poverty that led to some ethnic groups having restricted access, whereas other members of the group argued that ethnic origin could in itself act as a barrier.

In addition to these sources of feedback, the tutor also received some informal student feedback in the form of one-to-one comments offered by students in person or via email. These noted how much they had enjoyed the presentation exercise. Indeed, one student had become so enthused by the topic that she went on to base her dissertation research on an investigation of the barriers to development of the information society in the Arab States.

\subsection{Student learning}

As with the evaluation of student reaction, it was possible to draw on a number of sources in order to measure students' learning and their achievement of learning objectives. These sources included the marks awarded for both the oral presentations and the written assignments; comments from the internal moderator and the external examiner; and the quality of debate on the group discussion boards. It is almost impossible at this level to disaggregate with any degree of reliability the role of the assessment strategy from other aspects of the module learning and teaching strategy in helping students to achieve these learning objectives. Nevertheless, if we give credence to the claim that assessment drives student learning (Brown and Knight, 1994), then we can safely assume that the assessment strategy will have impacted significantly on levels of student achievement. In the event, some outstanding work was produced, and all of the students completed the module successfully. Despite their initial fears concerning having to undertake group work, and to present their group's work to the rest of the cohort, they rose to the challenge. Moreover, the seemingly difficult task of learning to write reflectively was achieved - albeit to a lesser or greater degree of perfection - by the entire group. The tutor's favourable impression of the work was corroborated by comments made by the module's internal moderator and the module's external examiner, who both commented on the very high standard of the students' written work.

\subsection{Module tutor's reflections}

I was very encouraged by the apparent success of this assessment strategy. For students, it appeared to engender a more independent approach to their own learning, as well as supporting the development of a range of employability skills. Above all, it seemed clear that, whatever their initial reservations about having to undertake group work, most of the students had enjoyed the challenge and had found the research to be an interesting exercise. The high quality of the students' work seemed to support the belief that they had learnt from, and engaged with, the exercise.

It should, of course, be noted that these students were all mature and highly motivated postgraduate learners. Whether the method would work equally well with a less mature undergraduate cohort is open to question; however, I believe that it has much to offer in terms of the learning journey involved, even if the end product is less well developed. 
With regard to improvements that could be implemented in future assessments of this nature, I am considering the use of WebPA, an online tool developed by the Engineering Centre for Excellence in Teaching and Learning (CETL) ${ }^{4}$ located at Loughborough University, to facilitate students to submit their own assessment of individual group member contributions to the process. Although this might encourage more equal participation and help to identify those not pulling their weight, it is also a concern that it might undermine the strong teamwork and sense of collective responsibility that could be seen to be prevailing here.

There are also some concerns that the increased popularity among students of social networking tools such as Instant Messaging and MySpace reduces the impetus to take advantage of university-based communication systems such as discussion forums on the VLE. This will exert a negative impact on the tutor's ability to monitor group progress and participation, making it necessary to ensure that such discussion forums offer 'added value' through active tutor participation in offering formative feedback. An alternative approach might be to include an element of formal assessment based on forum participation, but this again risks undermining the genuinely collaborative approach and student ownership of the task that was such a strong feature of this exercise.

Another issue that arose as a result of this particular assessment was the fact that a significant number of students were not familiar with the use of Powerpoint. Although it was made clear to them that they did not have to use Powerpoint in their presentations, they certainly seemed to believe that this was a requirement. Therefore, it is necessary to ensure that students have access to training and support in the use of Powerpoint, if they are required to undertake this kind of exercise. It is, after all, an extremely useful employability skill. Similarly, I was surprised at the difficulty that students encountered when faced with having to write in a reflective style, and would therefore recommend that support for this should also be made available as a matter of course.

\section{CONCLUSION}

Overall, it is suggested that the combination of group research and presentation together with an individual written reflective account proved to be a valid approach to teaching ILS students about ethical and social issues. Rather than being 'told what to think', this approach required them to reach their own conclusions. These were not based solely on the existing research evidence, but were also the outcome of extensive group debate in which they openly challenged each others opinions and understanding. The specific nature of the research task encouraged students to engage with a broader international context: it is ironic, perhaps, that at the same point in time that we have entered an era of globalisation, the teaching of comparative librarianship and information work appears to have more or less "dropped off" the ILS curriculum. The combination of group work, presentation and organisational skills involved here, together with the encouragement of a reflective approach to their work, should surely support their future professional development in the workplace.

\section{REFERENCES}

Brock, S., (2003), Solving problems in nursing? Integrating problem based learning within the preregistration nursing curriculum, In Learning and Teaching Projects 2001/2. Wolverhampton University, Wolverhampton

Brown, S. and Knight, P., (1994) Assessing Learners in Higher Education, Kogan Page, London

Chartered Institute of Library and Information Professionals (CILIP), (2004) Body of Professional Knowledge, CILIP, http://www.cilip.org.uk/qualificationschartership/bpk (accessed 25 January 2007)

Drew, S. and Bingham, R., (2001), The Student Skills Guide, $2^{\text {nd }}$ ed., Gower, Aldershot

Forsyth, I., Jolliffe, A. and Stevens, D., Evaluating a course: practical strategies for teachers, lecturers and trainers, $2^{\text {nd }}$ ed., Kogan Page, London (1999)

Gorman, M., (2004), Whither library education?, New Library World. 105 (9), pp.376-380

Jones, R.E.J. and Cooke, L. (2006) A Window into Learning: Case Studies of Online Group Communication and Collaboration, Alt-J: Research in Learning Technology, 14 (3), pp.261-274

Kirkpatrick, D.L., (1977), Evaluating training programmes: evidence vs. proof, Training \& Development Journal, $11(9-12)$

Kolb, D. (1984), Experiential Learning, Prentice Hall, London

\footnotetext{
${ }^{4}$ See http://www.engcetl.ac.uk/ [Last accessed 25 January 2007]
} 
Martin, R., (1989), Public Libraries as Employers, Journal of Library Administration, 11 (3/4), pp.175-186

McAllister, G. and Alexander, S., (2003), Key aspects of teaching and learning in information and computer sciences, In A Handbook for Teaching and Learning in Higher Education, $2^{\text {nd }}$ ed., edited by Fry, H., Ketteridge, S. and Marshall, S., Kogan Page, London

Norris, P., (2001), Digital divide: civic engagement, information poverty and the internet, Cambridge University Press, Cambridge

Quality Assurance Agency, (2000), Librarianship and Information Management: Subject Benchmark Statement, Quality Assurance Agency, London. Also available online at http://www.qaa.ac.uk/academicinfrastructure/benchmark/honours/librarianship.pdf (accessed 25 January 2007)

Savin-Baden, M., (2000) Problem-Based Learning in Higher Education: Untold Stories, SRHE / Open University, Buckingham. 